Naturwissenschaften 81. 320-323 (1994) (c) Springer-Verlag 1994

\title{
Hereditary Sensorineural Hearing Loss in a Bird
}

\author{
O. Gleich* and G. M. Klump
}

Institut für Zoologie der Technischen Universität München, D-85747 Garching

\section{R. J. Dooling}

Department of Psychology. University of Maryland, College Park, MD 20742, USA

The avian cochlea is the principal model for the investigation of hair-cell regeneration and the recovery of function in the vertebrate auditory periphery [1]. This capacity for repair in birds would seem to preclude permanent sensorineural hearing loss involving hair cells. which is the most common cause of hearing disabilities in humans [2]. Here, we report the first evidence of a permanent sensorineural hearing loss in a bird. This loss is due to missing and abnormal hair cells and consequent physiological malfunction of the cochlea.

Belgian Waterslager canaries have been bred for nearly 100 years for specific song characteristics and their contact calls are especially low pitched. Very carly reports indicate that a high proportion of these birds produced faulty song compared to German canary strains [3]. Since canaries learn their songs from an external model and also rely on auditory

\footnotetext{
* Present address: HNO-Klinikum der Universität Regensburg. Postfach. D-93042 Regensburg
}

feedback [4]. these early reports may represent the first evidence of damaged hearing in this strain. The behavioral audiograms of Belgian Waterslager canaries reveal an inherited hearing disorder resulting in threshold shifts of 20-40 $\mathrm{dB}$ at high frequencies compared to canaries of other strains [5.6] (Fig. 1A). Such a permanent hearing loss is intriguing in a class of vertebrates with the ability to repair the auditory sensory epithelium.

We investigated the cause of the hearing loss in 1-2-year-old canaries (Serinus canarius) of the Belgian Waterslager strain by measuring behavioral thresholds, compound action potentials (CAP), and cochlear microphonic potentials (CM) as well as middle-car reflectance. An operant conditioning technique was used to determine behavioral thresholds [5]. For the measurements of CAP. CM. and the middle-ear reflectance. the birds were initially ancsthetized by injections of Xylazine (20) $\mathrm{mg} / \mathrm{kg}$ ) and Ketamine (40 $\mathrm{mg} / \mathrm{kg}$ ), additional doses were given to maintain a deep anesthesia throughout the surgery and experiments. Body temperature was maintained by an electric heating system. Surgical procedures to gain access to the base of the cochlea were according to [7]. For the recording of CM and CAP, a Teflon-coated silver-wire electrode was inserted in to the recessus scalac tympani or placed upon the round window membrane. A custom-built microcomputer board for recording evoked potentials digitally generated the stimuli (10)-ms tone pips, 1-ms Gaussian ramps, rate $3-4 \mathrm{~s}^{-1}$. test frequencies 0.5 to $6 \mathrm{kHz}$ ) and recorded the inner-ear potentials that were amplified by a Grass P5 and bandpass-filtered. Stimuli were presented at random phase for CAP and constant phase for $\mathrm{CM} ; 64$ presentations were averaged. Stimulus levels varied in steps of $5 \mathrm{~dB}$, covering a range of $50 \mathrm{~dB}$ and starting approximately $10 \mathrm{~dB}$ below the threshold at the respective stimulus frequency. Threshold critcrion was a CAP amplitude of $6 \mu \mathrm{V}$ and a CM amplitude of $3 \mu \mathrm{V}$. Slopes of amplitude functions were determined by linear regression within $20 \mathrm{~dB}$ of detection threshold. A closed sound system with a metal tube that was sealed against the entrance of the meatus was used for stimulation. Two small probe microphones (Knowles E3024), inserted into the walls of the tube at two locations, measured amplitude and phase of the sound signals; the middle-ear reflectance at $3 \mathrm{kHz}$ was calculated from such measurements.

We then examined the morphology of the inner ear of these birds by scanning electron microscopy (SEM) for compari- 
son with physiological and behavioral measures. Methods for the histological cvaluation of the avian basilar papilla have been described elsewhere [8]. Photographs of the papillar surface were taken at low magnification to construct an overview and high-power SEM pictures (final magnification $200(0-400() \times$ ) were used to systematically reconstruct strips of $120-150 \mu \mathrm{m}$ width at positions 20,50 , and $80 \%$ from the basal end of the papilla. Hair-cell parameters were measured on these reconstructions. The experiments were conducted with permits according to local animal welfare regulations.

The behavioral thresholds determined in our control and Waterslager canaries resemble previously published data (Fig. 1A) and show elevated thresholds in Waterslagers, especially for frequencies above $2 \mathrm{kHz}$. Thresholds derived from compound action potentials representing the summated activity of the VIIIth nerve fibers were significantly elevated in Waterslager canaries compared to control canaries (Fig. 1B). At $1 \mathrm{kHz}$ and below, the average threshold difference between the two groups was about 15 $\mathrm{dB}$, while at frequencies of $2.5 \mathrm{kHz}$ and above it was about $40 \mathrm{~dB}$. The magnitude of this difference at the high frequencies corresponds well with results from behavioral audiograms of Waterslager canaries. The slopes of CAP amplitude-intensity functions from Waterslager canaries were similar to those of control canaries but the functions were shifted toward higher soundpressure levels. This shift accounts for the elevated CAP-threshold curves in the Waterslager canaries. The finding of decreased sensitivity in Waterslager canaries is also reflected in the CM data. At $1 \mathrm{kHz}$ and below, we found no significant difference in the CM threshold between Waterslager canaries and controls, while at frequencies above $1 \mathrm{kHz}$ there was on average a 20 - $\mathrm{dB}$ difference in the thresholds (Fig. 1C). The slopes of the CM amplitude-intensity functions did not differ between Waterslager and control canaries. For both groups, thresholds calculated from CAP and CM measurements were highly correlated (Waterslager: $r=0.85, p<0.001$; control: $r=0.70, p<0.001)$.

In order to investigate the cellular basis of the hearing loss, we examined the papillae of four Waterslager canaries with elevated thresholds as determined
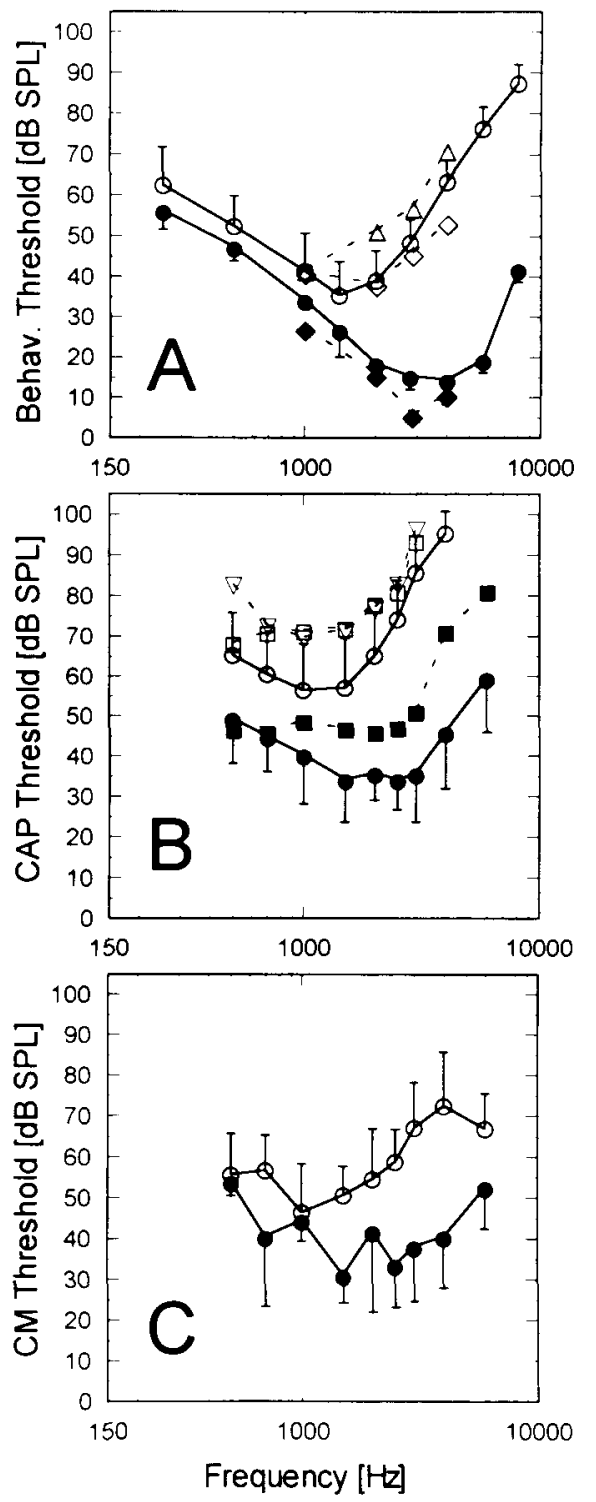

Fig. 1. Auditory threshold curves of Belgian Waterslager canaries (open symbols) shown in comparison to control canaries of other strains (filled symbols). The individual birds shown in this graph were included in the SEM analysis of the basilar papilla. A) Behavioral auditory threshold curves of birds from previous studies $[5,6]$ (circles and bars: means \pm SD) and of three individuals for which the basilar papilla is shown in Fig. 2 ( control 1, $\diamond$ Waterslager 1, $\triangle$ Waterslager 2). B) Average threshold curves determined from gross VIIIth nerve action potentials (compound action potentials, CAP, circles and bars: means \pm SD) of Waterslager canaries and control birds (CAP audiograms of birds included in the SEM analysis are also shown separately: control $2, \square$ Waterslager 3, $\nabla$ Waterslager 4). C) Threshold curves determined from cochlear microphonic potentials (CM, circles and bars: means \pm $\mathrm{SD)}$ from CAP measurements (see Fig. 1B) or behavioral audiograms (see Fig. IA) with the SEM. No abnormalities were evident in the external auditory meatus, the tympanic membrane, or the columella during dissection, confirming the results of the middle-car reflectance measurements, which also showed no significant differences between Waterslager canaries and canarics of other strains. However, SEM analysis of the basilar papilla revealed significant cochlear and hair-cell pathologies in Waterslager canaries (Fig. 2). The basilar papillac of three of the four Waterslager canaries investigated in detail were narrower and the total number of hair cells was smaller than in non-Waterslager canaries. In one Waterslager specimen the width of the basilar papilla and the number of hair cells across the papilla were similar to normal control canaries (Waterslager 1 in Figs. 1 and 2). In the most severely affected Waterslager specimen these values were reduced by more than $50 \%$ (Waterslager 2 in Figs. 1 and 2 ). Data averaged along the sensory epithelium indicate a reduction in papillar width by $20 \%$ and a reduction in haircell number across the papilla by $25 \%$ in Waterslager ears when compared to nonWaterslager canaries. Hair cells of Waterslager canaries also showed a reduced number of stereovilli per bundle and a larger surface area over most of the length of the papilla compared to those at corresponding positions in nonWaterslager canaries. Correlated with the larger hair cell surface area in Waterslager canaries, fewer hair cells were found over the width of the papilla. All Waterslager canary papillae also showed consistently distorted stereovillar bundles compared to other canaries. Some hair cells were devoid of stercovilli, while others showed abnormally small or large stereovilli. Because the bundles were so distorted, it was not possible to quantify hair-cell orientation in the Waterslager specimens for comparison with non-Waterslager canaries. Some hair cells were only covered with microvilli or showed small stereovillar bundles characteristic of regenerating hair cells [9].

Audiograms measured in Waterslagers at the age of 4-8 months demonstrate that they show already the typical elevated thresholds [6]. In addition, we found the hair-cell pathologies typical for Waterslagers in 2-month-old specimens (Fig. 

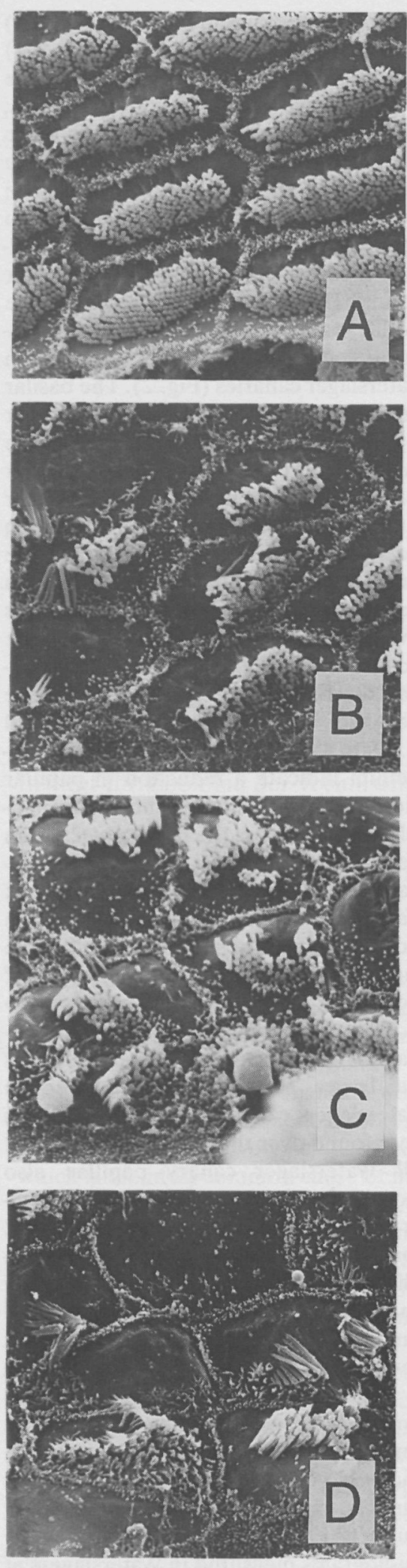

2D). Taken together, the results from CAP, CM, and behavioral measures of auditory sensitivity along with morphological abnormalities observed by
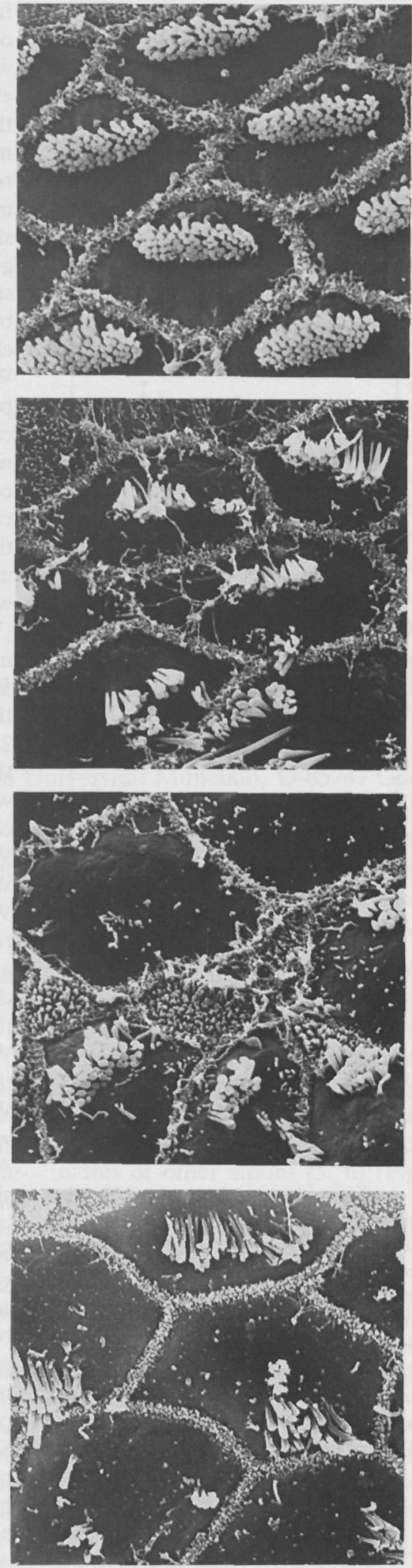

SEM show that Waterslager canaries have a hereditary sensorineural hearing loss that can be found early in life. Haircell damage in Waterslager canaries is
Fig. 2. Scanning electron micrographs of the basilar papillae of the three birds in which behavioral audiograms were determined and of a 2-month-old Waterslager (scale bar 10 $\mu \mathrm{m})$. The figure shows hair cells from the neural (left) and the abneural side (right) of the basilar papilla at about $50 \%$ from its basal end. A) The cochlea of a non-Waterslager canary with normal hearing ( control 1 in Fig. 1A) demonstrates a regular pattern of hair cells with orderly arranged, elongated stereovillar bundles. B) A surface view of the cochlea from the Waterslager specimen which showed the smallest degree of cochlear pathology ( $\diamond$ Waterslager 1 in Fig. 1A). C). This Waterslager canary $(\triangle$ Waterslager 2 in Fig. 1A) shows more severe abnormalities correlated with especially high behavioral threshold. D) Typical pictures from the basilar papilla of a 2-month-old Waterslager, demonstrating that these young birds already show abnormal basilar papillae

also found in the vestibular system [10], suggesting parallels with some combined auditory and vestibular neuroepithelial disorders observed in mammals such as mutant mouse strains and humans [2]. The Belgian Waterslager canary represents a model for a hereditary, permanent sensory hearing loss from a class of vertebrates that is well known for its potential for regeneration and repair of the sensory epithelium. Thus, this preparation should provide us with a unique opportunity to examine individual components of the repair and regeneration processes in the vertebrate auditory system.

The results of this study also raise interesting questions about our understanding of transduction in the avian auditory periphery. Data from behavior, CAP, and $\mathrm{CM}$ all show a prominent hearing loss at high frequencies, the magnitude of which varies with the degree of damage seen morphologically in SEM. Frequency-place maps from papillae of several avian species confirm that high frequencies are transduced at the basal end of the papilla [11]. In Waterslager canaries, however, distorted stereovillar bundles and a reduced number of stereovilli per bundle may alter the cochlear micromechanics which could result in an unusual frequency representation on the basilar papilla [12]. We cannot quantify the effects of different bundle pathologies on cochlear micromechanics. However, a reduction in the number of stereovilli per bundle (as found in Waterslager hair cells) will reduce the stiffness 
and thus the resonance frequency in the respective bundles. The highest frequencies represented on the basilar papilla of Waterslagers would thus be lower than in other canaries. In addition. the representation of low frequencies could be expanded. Furthermore, the distortion of stereovillar bundles might affect electrically tuned low-frequency hair cells less than high-frequency hair cells with predominant micromechanical tuning [13]. Testing these hypotheses in future experiments should help to explain why the hearing loss is more pronounced at high frequencies, whilc severe abnormalities in Waterslager cochleae are found along the whole length of the papilla.

Finally, the observations invite speculation about both the proximate and ultimate causes of hearing loss in Waterslager canaries. The sensorineural damage we observed in Waterslagers may have resulted from defective developmental or regenerative mechanisms in which abnormal hair cells are produced. Cells may also develop normally but the damage may occur continuously and at such a pace that the Waterslager's hair-cell repair mechanisms are not sufficient to restore a normal papilla. Regardless of the mechanism, the defect must have arisen early in the breeding history of the Belgian Waterslager strain, because it is widespread. The canaries reported here were drawn from three different populations in the USA and a fourth population in Germany and all subjects displayed hearing abnormalities. During World War I, the Waterslager breeding population in Belgium was severely reduced and only few birds survived. From this small gene pool the Waterslager line was reestablished by systematic breeding. Most of the present breeding populations probably originated from these Belgian colonies established in the years after the war [14]. This common origin may explain the similar pathologies in all Waterslagers. Perhaps canary breeders, through selection for specific song characteristics, have inadvertently selected for a genetic hearing defect.

We thank C. Carr, R. A. Code, W. Hodos, G. A. Manley, J. Strutz, and M. Vater for comments on a previous version of the manuscript. A. Linzenboldt measured the audiograms of three birds shown individually in Fig. 1A. H. Hudde advised us on the reflectance measurements. G. Schwabedissen helped with the histology. The experiments comply with the "Guide for the Care and Use of Laboratory Animals" NIH publication No. 86-23 revised 1985 and the laws of Germany and the USA. Supported by grants from the DFG to G. M. K. and G. A. Manley (SFB 204), a Helmholtz grant by the BMFT to O. G., the Alexander von Humboldt Foundation (Forschungspreis to R. J. D.), and the NIH (grants DC00198 and MH00982 to R. J. D.). Parts of the data were presented at the 20th Göttingen Neuroscience Meeting 1992, and at the Midwinter Meeting of the Association for Research in Otolaryngology 1993.

Received May 2, 1994

1. Cotanche, D. A.: Hear. Res. 30, 181 (1987); Cruz, R. M., Lambert, P. R., Rubel, E. W.: Arch. Otolaryngol. Head Neck Surg. 113, 1058 (1987); Corwin, J. T., Contanche, D. A.: Science 240, 1772 (1988); Ryals, B. M., Rubel, E. W.: ibid. 240, 1774 (1988)
2. Steel, K. P.: Ann. N. Y. Acad. Sci. 630. 68 (1991)

3. Güttinger, H. R.: Behaviour 94, 254 (1985); Okanoya, K., Dooling, R. J., Downing, J. D.: Hear. Res, 46, 271 (1990); Sandfort, I.: Kanarienfreund 42, 414 (1989); Kluhs, W. (1912) cf. Sandfort, J.: ibid. 43, 324 (1990)

4. Waser, M. S., Marler, P.: J. Comp. Physiol. Psychol. 91, 1 (1977); Marler, P., Waser, M. S.: ibid. 91, 8 (1977)

5. Okanoya, K., Dooling, R. J.: J. Acoust. Soc. Am. 78, 1170 (1985)

6. Okanoya, K.. Dooling, R. J.: J. Comp. Psychol. 101, 213 (1987); Okanoya, K., Dooling, R. J., Downing, J. D.: Hear. Res, 46, 271 (1990)

7. Manley, G. A., Gleich, O., Oeckinghaus, H., Leppelsack, H.-J.: J. Comp. Physiol. A 157, 161 (1985)

8. Gleich, O., Manley, G. A.: Hear. Res. 34, 69 (1988)

9. Cotanche, D. A.: ibid. 30, 181 (1987): Corwin, J. T., Cotanche, D. A.: Science 240, 1772 (1988); Hashino, E., Tanaka, Y., Sokabe, M.: Hear. Res. 52, 356 (1991); Pickles, J. O., Rouse, G. W.: ibid. 55, 244 (1991)

10. Park, T. J., Lu, Y., Weisleder, P.: Soc. Neuro. Abstr. 23, 1579 (1993)

11. Manley, G. A., Brix, J., Kaiser, A. Science 237, 655 (1987); Gleich, O.: Hear. Res. 37, 255 (1989); Köppl, C., Gleich, O., Manley, G. A.: J. Comp. Physiol. 171, 695 (1993); Gummer, A. W., Smolders, J. W. T., Klinke, R.: Hear. Res. 29, 63 (1987)

12. Holton, T., Hudspeth, A. J.: Science 222, 508 (1983); Frishkopf, L. S., DeRosier, D. J.: Hear. Res. 12, 393 (1983)

13. Manley, G. A., Gleich, O., in: The Evolutionary Biology of Hearing, p. 561 (D. B. Webster, R. R. Fay, A. N. Popper, eds.). New York: Springer 1992

14. Peleman, B. (1922), cf. Sandfort J.: Kanarienfreund 42, 470 (1989) 